\title{
Assessment of Lithuanian power supply security depending on nuclear energy
}

\author{
J. Augutis ${ }^{1}$, R. Krikštolaitis ${ }^{1}$, V. Matuzienè ${ }^{2} \&$ S. Pečiulyte ${ }^{1}$ \\ ${ }^{I}$ Department of Mathematics and Statistics, \\ Vytautas Magnus University, Lithuania \\ ${ }^{2}$ Laboratory of Nuclear Installations Safety, \\ Lithuanian Energy Institute, Lithuania
}

\begin{abstract}
The Lithuanian energy sector is one of the most significant and problematic branches of its economic sector. One of the main threats to the security of the power supply in Lithuania is the closure of the Ignalina nuclear power plant (NPP).

The Lithuanian power supply is assessed in terms of security indicators in this paper. Indicators are the parameters of the nuclear chain. A system of 22 indicators was formed in the study. The indicators were divided into four blocks: technical, economical, socio-political, and environmental. Threshold values of some indicators, employed in simulations, were obtained using an expert assessment and functional interdependences methods. In this paper the security level of the Lithuanian power supply from a nuclear energy point of view is determined.
\end{abstract}

Keywords: assessment of power supply security, security indicators, nuclear sector.

\section{The importance of security level assessment for the Lithuanian nuclear energy sector}

The objective of this study is to perform an assessment of the dependence of the Lithuanian power supply on the nuclear sector using a security indicators system.

The nuclear sector is one of the most sensitive sectors from the viewpoint of security of power supply due to its magnitude and economy of scale of NPPs, and due to dependence on government policy. Besides, the acceptance of public 
and proper probabilistic assessment of experts is an important condition in order to ensure the operation of NPPs.

The issues of the nuclear sector in Lithuania are essential ones since, in this country, the biggest share of electricity is generated by one NPP reactor. Such a situation is unique in the whole of Europe. In accordance with IAEA data, in $2007,72.2 \%$ of electricity was generated in the Lithuanian nuclear sector. The country does not have its own primary energy sources: coal, oil, natural gas, and uranium or a possibility to use huge hydro energy resources. Lithuania is mostly dependent on one country supplier - Russia.

The topic of security of the nuclear sector supply for Lithuania became more relevant after closing Ignalina NPP Unit 1 in 2004 and planning how to provide electricity after shutting down Unit 2 at the end of 2009. The Lithuanian government in co-operation with other Baltic countries (Latvia, Estonia) and Poland is planning to build new the Visaginas NPP in Lithuania, before 2018.

Moreover, security of the power supply has recently gained importance on the policy agenda due to the growing dependence of industrialized economies on energy consumption and the increased frequency of supply disruption. Security of energy supply includes mining, conversion and transportation of primary energy sources, generation, distribution and supply of energy to final consumers. Security of power supply is an important issue for the functioning of infrastructure, the security of life and of society from the technical, economical, socio-political and environmental point of view.

It should be noted that the energy security concept is presently represented differently in various sources of literature [2, 3]. Mentioned definitions of security of power supply highlight national interests related to energy sources supply.

Our task is to assess the level of power supply security depending on the nuclear sector using scientific methods. The adopted methodology of assessment could be useful in proposing recommendations to decision makers due to improvement of energy supply security level.

In general, it could be stated that security of the power supply is a complex field of research, based on geopolitical analysis, economic modelling, probabilistic safety analysis (PSA) of power plant, and socio-political and environmental research. The results of the above mentioned models, experts' judgments and statistical data are used as security indicators of energy supply. According methodology of Bykova [1] and improvements made by authors, the integral index of energy sector assessment is obtained, which can be compared to others according time and scenarios, and which enables making conclusions on security levels.

\section{Methodology}

The authors have developed a new security indicator system, which comprises indicators of different dimensions, assessing the aspects of different fields: technical, economical, socio-political and environmental. In order to integrate indicators to one assessment system, i.e. to get one measure, normalisation 
methods of indicators are used, their interdependencies are assessed, weights of indicators are defined, and threshold values of assessment are introduced. Using the security indicators, the level of certain energy system is assessed. The separate disturbance scenarios of energy system security supply can be compared to each other. The assessment enables to present recommendations to decision makers concerning existing level of certain energy system. Comparing the scenarios of energy supply disturbances, there is a possibility to choose the most hazardous of them and to investigate what measures are necessary in order to avoid the disturbances. In order to observe the influence of separate indicators on the entire system, it is important to perform a sensitivity analysis in the future works. The comparison of energy systems of different countries would give moreover clearness for actions of decision makers towards strengthening of energy supply security.

The methodology of security indicators is chosen for assessment of nuclear sector security due to possibility to relate indexes of different fields and derive an integral value of security level.

\subsection{The system of security indicators}

Security indicator is a special index which gives numerical values to important issues for security of the energy sector. Energy security levels can be assessed by a set of indicators normalized in a certain way, because separate indicators have different measures. Using indicators we can evaluate both the state of the country's security of electric energy supply and separate parts of the country's energy sector, e.g. transport or nuclear sector.

In literature various energy security indicators are available, which are considered as measures for assessment of energy security. The World Energy Council has proposed a set of indicators of energy threats. The system is essentially based on the work of Gnansonou [4]. ECN and the Clingendael Institute of The Netherlands have developed a set of two indicator systems: crisis capability index and supply / demand index [5]. The United Kingdom's White paper establishes the main indicators dealing with security and/or vulnerability of an energy system [6]. Finnish researchers assessed the energy security by indicators through the facilities of interdependencies and threat analysis [7]. They found that international trade in energy resources, diversification of suppliers, improved intersystem relations, and integrated markets, new energy storages also are a reliable, efficient and economical way to ensure energy independence. The scientists of the Joint Research Centre, assessing the risk of energy sector, related indicators with probabilistic analysis [8]. According to their methodology, it is possible to perform risk comparison of all energy technologies in different cycles using PSA methods. Moldovan scientist Bykova presented an indicator system comprised of 7 blocks [1], which describes in detail the economic side of an energy supply. In the paper not only expert assessment is presented, but also a functional interdependencies method for evaluation of indicator values. Under this method the macro economical indicators (such as GDP and energy sector) are interconnected, therefore, while assessing energy security, a meaningful link remains between the economy and 
energy of the country. It should be mentioned that no study was found where the indicators of different fields would be used.

The indicator system must meet certain requirements to be suitable for assessment of the analysed object. In particular, a detailed assessment of the indicators is carried out by Burgherr et al. in the $6^{\text {th }}$ Framework Programme NEEDS project [9]. The main principles of indicators, presented in the work, are science-based, functional, and pragmatic ones. Since the task to assess security of energy supply is interdisciplinary, the blocks (technical, economical, sociopolitical and environmental) should represent these fields.

Besides, usually it is not only important to assess the current state of security of energy supply, but also to predict what will happen after implementing some technologies in the time period. Therefore, statistical data, predictions and experts' judgments should be used in the application of the methodology. The assessment of security of energy supply is performed for the period 2005-2020. The time frame includes both the shutdown of Ignalina NPP at the end of 2009 and the construction of new NPP by 2018. The period between these two events is important in providing an energy standpoint. The first part of thermal power plants should begin to start generation in 2012, after a few years more of them should enter into the working cycle. According the current strategy, Lithuania should connect to the Union of Coordination and Transmission of Energy (UCTE) in the period 2012-2015.

As it was mentioned before, data for indicator systems can be received from statistical data, economical modelling [10], reliability modelling or experts' judgement, social/political assessment, which often is based on hypothetical probabilities received from lognormal distribution [11-13].

Security indicator systems can be changed depending on the assessment system or subjectivity of researchers or decision makers. One of possible indicators system examples for nuclear sector is presented in Table 1. The indicators system, depending on the situation or country, may be extended.

The indicators as heavy accidents with release of radioactive substances and heavy accidents with reactor core damage are considered as the most important accidents in the nuclear sector. Considerable attention is paid to forecasting of PSA probabilities in the Lithuanian Energy Institute (LEI) [14]. The lifetime of NPPs is considered an important index in the nuclear sector. The experts' analyses are performed in order to prolong the NPPs lifetime, which usually is about 40 years. The installed capacity utilization factor shows the generated energy percentage in the total installed energy capacity. The quantity of the ungenerated electricity appears due to disorders of facilities' work (forced stopping and discharges). The indicator is considered as one of the most important indexes of energy security as it shows what quantity is available to the consumer, comparing with ungenerated and unsupplied energy. Though installed capacity in Ignalina NPP is $1500 \mathrm{MW}$, according to the rules of the Lithuanian State Nuclear Power Safety Inspectorate (VATESI) the values of utilization of installed capacity and ungenerated energy are assessed according to the installed capacity of $1300 \mathrm{MW}$ in block. The value of ungenerated electric energy occurs 
Table 1: $\quad$ Security indicators system for the Lithuanian nuclear sector.

\begin{tabular}{|c|c|c|c|}
\hline $\mathrm{NO}$ & INDICATOR & $\begin{array}{l}\text { Direction } \\
\text { of scale }\end{array}$ & UNIT \\
\hline 1 & TECHNICAL & & \\
\hline 1.1 & $\begin{array}{l}\text { Heavy accidents with release of radioactive materials } \\
\text { to the environment } X_{11}\end{array}$ & $\min$ & $\begin{array}{l}\text { Freq./ } \\
\text { probab. }\end{array}$ \\
\hline 1.2 & Heavy accidents with reactor core damage $X_{12}$ & $\min$ & $\begin{array}{l}\text { Freq./ } \\
\text { probab. }\end{array}$ \\
\hline 1.3 & Lifetime of nuclear installations $X_{13}$ & $\min$ & Years \\
\hline 1.4 & Installed capacity utilization factor $X_{14}$ & $\max$ & $\%$ \\
\hline 2 & ECONOMICAL & & \\
\hline 2.1. & $\begin{array}{l}\text { Part of electric energy produced in NPP in total } \\
\text { amount of produced electric energy } X_{21}\end{array}$ & $\min$ & GWh \\
\hline 2.2 & Part of nuclear fuel in total fuel amount $X_{22}$ & $\min$ & ktne \\
\hline 2.3 & Nuclear fuel consumption per person $X_{23}$ & $\max$ & ktne \\
\hline 2.4 & Part of imported electricity $X_{24}$ & $\min$ & GWh \\
\hline 2.5 & The electricity price in Ignalina NPP $X_{25}$ & $\min$ & $\mathrm{ct} / \mathrm{kWh}$ \\
\hline 2.6 & $\begin{array}{l}\text { The electricity price in other power stations of } \\
\text { Lithuania } X_{26}\end{array}$ & $\min$ & $\mathrm{ct} / \mathrm{kWh}$ \\
\hline 2.7 & $\begin{array}{l}\text { The electricity price in new combined cycle power } \\
\text { stations } X_{27}\end{array}$ & $\min$ & $\mathrm{ct} / \mathrm{kWh}$ \\
\hline 2.8 & The electricity price in new NPP $X_{28}$ & $\min$ & $\mathrm{ct} / \mathrm{kWh}$ \\
\hline 2.9 & The amount of imported gas $X_{29}$ & $\min$ & $€ / \mathrm{MWh}$ \\
\hline $\begin{array}{c}2.1 \\
0\end{array}$ & $\begin{array}{l}\text { The degree of Lithuania electric energy participation } \\
\text { in West Europe electric energy market } X_{210}\end{array}$ & $\max$ & $\%$ \\
\hline 3 & SOCIO-POLITICAL & & \\
\hline 3.1 & $\begin{array}{l}\text { Part of supplied nuclear fuel from dominant supplier } \\
X_{31}\end{array}$ & $\min$ & $\%$ \\
\hline 3.2 & Threat of terrorist attacks $X_{32}$ & $\min$ & $\begin{array}{l}\text { Freq./ } \\
\text { probab. }\end{array}$ \\
\hline 3.3 & Good public opinion due to nuclear plants $X_{33}$ & $\max$ & $\begin{array}{l}\text { Freq./ } \\
\text { probab. }\end{array}$ \\
\hline 3.4 & $\begin{array}{l}\text { The probability of negative political decisions } \\
\text { according to nuclear fuel (in countries, wherewith } \\
\text { Lithuania electric energy system is related to) } X_{34}\end{array}$ & $\min$ & $\begin{array}{l}\text { Freq./ } \\
\text { probab. }\end{array}$ \\
\hline 3.5 & $\begin{array}{l}\text { The probability, that electricity network initial } \\
\text { reserve will not be supported } X_{35}\end{array}$ & $\min$ & $\begin{array}{l}\text { Freq./ } \\
\text { probab. }\end{array}$ \\
\hline 3.6 & $\begin{array}{l}\text { The probability of negative decisions due to nuclear } \\
\text { installations supply } X_{36}\end{array}$ & $\min$ & $\begin{array}{l}\text { Freq./ } \\
\text { probab. }\end{array}$ \\
\hline 4 & ENVIRONMENTAL & & \\
\hline 4.1 & $\begin{array}{l}\text { Radiation (to person per year) due to nuclear sector } \\
\text { on normal operation } X_{41}\end{array}$ & $\min$ & $\mathrm{mSv}(\mathrm{Bq})$ \\
\hline 4.2 & $\begin{array}{l}\text { Hazards due natural disasters (extreme winds, } \\
\text { external fire, external flooding and extreme showers, } \\
\text { etc.) } X_{42}\end{array}$ & $\min$ & $\begin{array}{l}\text { Freq./ } \\
\text { probab. }\end{array}$ \\
\hline
\end{tabular}


due to planned preventive maintenance, compulsorily outages, related to facility defects, and restrictions of load controls.

Economic indicators assess the price of energy $\left(X_{25^{-}} X_{28}\right.$ indicators $)$ and the amount of energy generated in nuclear sector $\left(X_{21}-X_{22}\right.$ indicators). The share of electric energy produced in NPP in total amount of produced electric energy shows the share of generated electricity in the NPP as it is important that electricity would be generated using different technologies. Indicator $X_{23}$ shows consumption of nuclear fuel per person. Scale direction of indicator is the maximum as here it is important availability for consumption in energy supply security point of view. Indicator $X_{24}$, the amount of imported electricity, shows the dependence of country on the final energy supply. Indicators $X_{25}-X_{28}$ are electricity prices, using different methodologies in Lithuania. The classifying of prices enables to assess differences among electricity prices in different technologies. In case of integrating all prices to one indicator value, including taxes, the general indicator wouldn't reflect differences in technologies' costs. The weight of an indicator becomes zero in case any power plant is out of operation. Gas is also a very important fuel used in the Lithuanian energy sector. Therefore, it is very important to evaluate the changes of its part, evaluating energy security (indicator $X_{29}$ ). Stronger Lithuanian integration to Western Europe means bigger possibilities to participate in the wider energy and fuel market. Therefore, the growth of index $X_{210}$ would show important positive change towards energy security.

We should note that socio-political sub-block includes not only social (indicator $\left.X_{33}\right)$, political $\left(X_{34}-X_{36}\right)$, but also geopolitical $\left(X_{31}\right)$ and terrorist $\left(X_{32}\right)$ assessment. Part of the supplied nuclear fuel from a dominant supplier shows the ability of a country to provide itself with energy sources due to geographical and political features. The probability of terrorist attacks is necessary to full energy security assessment. One of a probable large-scale event is of an aircraft crash on the territory of the NPP. One of the studies is performed in LEI [15]. Public opinion on the nuclear sector is a very important index to Lithuania, which is planning to build NPP. It shows knowledge of society about energy security and understanding the importance of nuclear sector in it. Probabilities of negative decisions of suppliers or not supporting reserves are very meaningful to the countries, which import the biggest share of fuel from one supplier. Although the indexes are the most difficult to forecast, since there is low experience of experts in this field, the probability can be considered as hypothetical and lognormal scale is used to determine it.

From the environmental point of view radioactivity is an important index in the nuclear sector. It concerns society and VATESI determines norms of radioactivity in normal operation of NPP. Radioactivity in normal operation is very small in comparison to doses, which are received by man in everyday life (in closed rooms, getting some medical procedures, flying by plane, etc.). Researches of hazards due to natural disasters are also constantly performed by PSA for NPPs. Usually the probabilities depend from the area of NPP. 


\subsection{The algorithm of energy security level assessment}

The security of energy supply assessment using indicators algorithm can be briefly outlined as: developing of data; gathering of the factual indicator values; calculation of indicators' threshold values; calculation of normalised indicators values; creation of each indicator critical scale; assessment of each indicator in marks by critical scale; evaluation of every indicator changes dynamics during the researching period; assessment of state of block and whole object, which is under consideration (energy system, region, country, enterprise, etc.); uncertainty analysis of the data, sensitivity and importance analysis of indicators weight; presentation of recommendations regarding security level support and improvement.

As was mentioned in a previous section, statistical data, experts' judgments, reports and modelling have been used for gathering the factual indicator values. Indicator is described by name, base and threshold values. The base value of an indicator is the value when the indicated system state is normal. The threshold values reveal when the indicated system state is pre-critical or critical. Exact threshold values of indicators can be calculated using different methods [1, 8]. In this paper we use expert assessment and functional interdependencies methods for estimation of the indicator threshold values.

Each indicator is denoted as $X_{i j k}$, where $i=1, \ldots, n$ - number of block, $j=1, \ldots$, $m$ - a row number indicator in the block, $k=1, \ldots, l$ - iteration number (iteration number depends on the number of modelling years). Using expert assessment methods, first of all, pre-critical $X_{i j}^{p c}$ and critical $X_{i j}^{c}$ values of each indicator were calculated according formula (1) and (2), respectively:

$$
\begin{aligned}
X_{i j}^{p c} & =X_{i j}^{b} \frac{p c t v_{i j}}{100} \text { or } X_{i j}^{p c}=X_{i j}^{b} \frac{1+p c t v_{i j}}{100}, \\
X_{i j}^{c} & =X_{i j}^{b} \frac{c t v_{i j}}{100} \text { or } X_{i j}^{c}=X_{i j}^{b} \frac{1+c t v_{i j}}{100}
\end{aligned}
$$

where $X_{i j}^{b}$ - base value of indicator, $p c t v_{i j}$ - pre-critical threshold value of indicator, $c t v_{i j}$ - critical threshold value of indicator. Pre-critical and critical threshold values of indicators are evaluated by experts in $100 \%$ scale taking into account the investigated state of Lithuanian energy system. Then, we calculate normalised pre-critical (3) and critical values of an indicator, which will be used for establishing the evaluation scale.

$$
X_{i j}^{n p c}=X_{i j}^{p c} / X_{i j}^{c} .
$$

Normalised critical values of indicators $X_{i j}^{n c}=1$.

Since in different blocks indicators are measured using different measuring units, the values of indicators are joint into one form, i.e. normalised values of each indicator are calculated (4):

$$
X_{i j k}^{n}=X_{i j k} / X_{i j}^{c} .
$$


Threshold values of indicators were calculated also using method of functional interdependencies [1]. In such a case one basic indicator is needed. The costs of nuclear energy system $I_{\text {nec }}$ were used as basic indicator. In the modelling a presumption is made that during the analysed period the costs of nuclear energy system will not exceed the appropriate part (for example, 25\%) from the base year costs, i.e. $I_{\text {nec }}=0.25$. Calculating indicator $I_{\text {nec }}$ for each following year a discount norm is introduced. Further the connections of all blocks are determined. $I_{n e c}$ value is instantly attributed to the independent blocks. Threshold values of interdependent blocks are calculated using formula:

$$
I_{i}^{t}=\sqrt[r]{I_{n e c}}, i=1, \ldots, n
$$

where $r$ - number of interdependent blocks. Further in each block interconnections of indicators are identified. The threshold values of indicators are calculated according to the interdependencies between indicators, to the base value and to the threshold values of blocks. In the functional interdependencies method pre-critical, critical and threshold values of indicators are dependent on the iteration number (different as in expert assessment method):

$$
\begin{aligned}
& X_{i j k}^{p c}=X_{i j k} \frac{p c t v_{i j k}}{100} \text { or } X_{i j k}^{p c}=X_{i j k} \frac{1+p c t v_{i j k}}{100}, \\
& X_{i j}^{c}=X_{i j k} \frac{c t v_{i j k}}{100} \text { or } X_{i j}^{c}=X_{i j k} \frac{1+c t v_{i j k}}{100} .
\end{aligned}
$$

Normalised pre-critical values of indicators are calculated according to formula:

$$
X_{i j}^{n p c}=\frac{1}{l} \sum_{k=1}^{l} X_{i j k}^{n p c}
$$

where $X_{i j k}^{n p c}=X_{i j k}^{p c} / X_{i j k}^{c}$. Critical value of each indicator is equal:

$$
X_{i j}^{c}=\frac{1}{l} \sum_{k=1}^{l} X_{i j k}^{c} .
$$

Normalised values of indicators using functional interdependencies method are calculated also using formula (4), where $X_{i j}^{c}$ is from formula (9).

Normalised pre-critical and critical threshold values of indicators determine the limit when the system transfers to the pre-critical and critical state. A scale is used to determine a system state. The state of each indicator for the analysed year is evaluated in the scale from 1 to 8 . The scale is divided into three main parts - normal ( 8 points), pre-critical and critical. Respectively, pre-critical part of the scale is divided into the initial (ipc, 7 points), extending (epc, 6 points) and critical (cpc, 5 points), whereas the critical into unstable (uc, 4 points), menacing (mc, 3 points), critical (cc, 2 points) and extreme (ec, 1 point) parts. The precritical zone for each indicator is divided into three equal parts. The critical zone is divided into smaller parts, using weight coefficients $1.2 ; 1.4$ and 1.6 [13] and for all indicators they are the same: uc- $1-0.83, \mathrm{mc}-0.83-0.71, \mathrm{cc}-0.71-0.63$, ec $-0.63-0$. 


\section{Investigation of the Lithuanian power energy supply security state}

The system comprised of 22 indicators was created (see Table 1) to investigate the state of security level of Lithuanian power supply dependence on nuclear energy. Values of indicators are calculated for the period 2005, 2006, 2007, 2010, 2015, 2018 and 2020. The state of indicators in technical, socio-political and environmental blocks is established by experts in points directly. Indicators $X_{11}$ and $X_{12}$ in the technical block and all indicators in the environmental block are normal state for all analysed period. Indicators $X_{13}$ and $X_{14}$ are normal state, except in 2010 and 2015, they are extreme critical state. Indicators in the sociopolitical block vary from 8 points (normal state) to 3 points (menacing critical state). State of the economical block indicators was calculated using expert assessment and functional interdependencies methods. Base values of economical block indicators are: $X_{21}-X_{23}-30 \%, X_{24}-X_{29}-0 \%$ and $X_{210}-100 \%$. Pre-critical threshold values defined by expert assessment method $\left(\right.$ pctv $\left.v_{i j}\right)$ are the following: $X_{21}-X_{23}, X_{210}-70 \%, X_{24}-X_{29}-30 \%$; whereas critical threshold values $\left(c t v_{i j}\right)$ are $X_{21}-X_{210}-50 \%$. Using these pre-critical and critical threshold values, normalised values of indicators were calculated by formulae (1) - (4).

In order to use functional interdependencies method, first of all, interconnections between blocks must be established. They are given in Table 2 .

Economical block threshold value is calculated by formula (5), where $r=4$, and introducing 8\% discount norm for each following year (see Table 3 ).

Table 2: $\quad$ Interconnections of blocks.

\begin{tabular}{|l|c|c|c|c|}
\hline Blocks & Technical & Economical & Socio-political & Environmental \\
\hline Technical & + & & + & + \\
\hline Economical & + & + & + & + \\
\hline Socio-political & + & + & + & + \\
\hline Environmental & & & & + \\
\hline
\end{tabular}

Table 3: $\quad$ Economical block threshold value $I_{2}^{t}$.

\begin{tabular}{|c|c|c|c|c|c|c|c|}
\hline Years & 2005 & 2006 & 2007 & 2010 & 2015 & 2018 & 2020 \\
\hline$I_{2}^{t}$ & 0.707 & 0.721 & 0.734 & 0.769 & 0.819 & 0.845 & 0.861 \\
\hline
\end{tabular}

The interconnections between indicators must be identified in the economical block: indicators $X_{21}, X_{22}$ and $X_{23} ; X_{21}, X_{22}$ and $X_{24} ; X_{21}, X_{23}$ and $X_{29}$ are dependent; and other indicators are independent. Thus, the critical threshold values of indicators, according to the base values of indicators, are calculated

$$
\begin{aligned}
& c t v_{21}=c t v_{22}=c t v_{23}=1-c t v_{24}=1-c t v_{29}=\sqrt[4]{I_{2}^{t}}, \\
& 1-c t v_{25}=1-c t v_{26}=1-c t v_{27}=1-c t v_{28}=c t v_{210}=I_{2}^{t} .
\end{aligned}
$$


Calculated threshold pre-critical values of indicators in the period 2005-2020 vary in intervals: pctv $_{21}-$ pctv $_{23}-28 \%-29.3 \%$, pct $_{24}$, pctv $_{29}-5 \%-2 \%$, pctv $25^{-}$ pctv $_{28}-7 \%-15 \%$ and pctv $_{210}-85 \%-93 \%$; whereas threshold critical values: $c t v_{21}-c t v_{23}-27 \%-28.5 \%, c t v_{24}, c t v_{29}-5 \%-11 \%, c t v_{25}-c t v_{28}-14 \%-29 \%$ and $c t v_{210}-71 \%-86 \%$. Further there are calculated normalised values of indicators by formulae (6) - (9) and (4).

For the evaluation of the Lithuanian power supply security level depending on nuclear sector there are important weights of blocks and indicators in each block. These weights of blocks are directly determined by experts: technical 0.2 ; economical -0.5 , socio-political -0.2 and environmental -0.1 . In Table 4 the weights of indicators are shown in technical, socio-political and environmental blocks. Weights of blocks and indicators, used in this research, are preliminary. They have explanatory, methodological purpose.

Weights of economical block indicators depend on analysed year, as some indicators are important just in exact year. We divided the investigated period 2005 - 2020 in four parts: 2005 - 2007 (Ignalina NPP is still operating), 2010 (Ignalina NPP is already closed); 2015 (new combined cycle power stations begin to work) and $2018-2020$ (new NPP is operating).

Using the assessment scale of indicator states and weights of indicators in the blocks, the state of each block is obtained (Table 6).

The state of all Lithuanian security of power supply system, according to nuclear energy, is presented in Figure 1.

Table 4: $\quad$ Weights of indicators.

\begin{tabular}{|c|c|c|c|c|c|c|c|c|c|c|c|}
\hline$X_{11}$ & $X_{12}$ & $X_{13}$ & $X_{14}$ & $X_{31}$ & $X_{32}$ & $X_{33}$ & $X_{34}$ & $X_{35}$ & $X_{36}$ & $X_{41}$ & $X_{42}$ \\
\hline 0.4 & 0.3 & 0.1 & 0.2 & 0.25 & 0.15 & 0.15 & 0.15 & 0.15 & 0.15 & 0.7 & 0.3 \\
\hline
\end{tabular}

Table 5: $\quad$ Weights of indicators in economical block.

\begin{tabular}{|c|c|c|c|c|c|c|c|c|c|c|}
\hline Years & $X_{21}$ & $X_{22}$ & $X_{23}$ & $X_{24}$ & $X_{25}$ & $X_{26}$ & $X_{27}$ & $X_{28}$ & $X_{29}$ & $X_{210}$ \\
\hline $2005-2007$ & 0.1 & 0.05 & 0.05 & 0.1 & 0.15 & 0.15 & 0 & 0 & 0.1 & 0.3 \\
\hline 2010 & 0.1 & 0.05 & 0.05 & 0.15 & 0 & 0.2 & 0 & 0 & 0.15 & 0.3 \\
\hline 2015 & 0.1 & 0.05 & 0.05 & 0.15 & 0 & 0.1 & 0.1 & 0 & 0.15 & 0.3 \\
\hline $2018-2020$ & 0.1 & 0.05 & 0.05 & 0.1 & 0 & 0.1 & 0.1 & 0.1 & 0.1 & 0.3 \\
\hline
\end{tabular}

Table 6: Assessment of block states in points.

\begin{tabular}{|l|c|c|c|c|c|c|c|}
\hline Block & 2005 & 2006 & 2007 & 2010 & 2015 & 2018 & 2020 \\
\hline Technical & 8.00 & 7.60 & 7.60 & 5.90 & 5.90 & 7.60 & 8.00 \\
\hline Economical (expert assess. m.) & 5.90 & 5.90 & 5.90 & 2.05 & 4.45 & 5.90 & 6.60 \\
\hline $\begin{array}{l}\text { Economical (funct. interdep. } \\
\text { m.) }\end{array}$ & 5.90 & 5.90 & 5.90 & 1.45 & 3.85 & 7.70 & 8.00 \\
\hline Socio-political & 2.95 & 2.95 & 2.95 & 6.95 & 7.40 & 6.95 & 6.95 \\
\hline Environmental & 8.00 & 8.00 & 8.00 & 8.00 & 8.00 & 8.00 & 8.00 \\
\hline
\end{tabular}




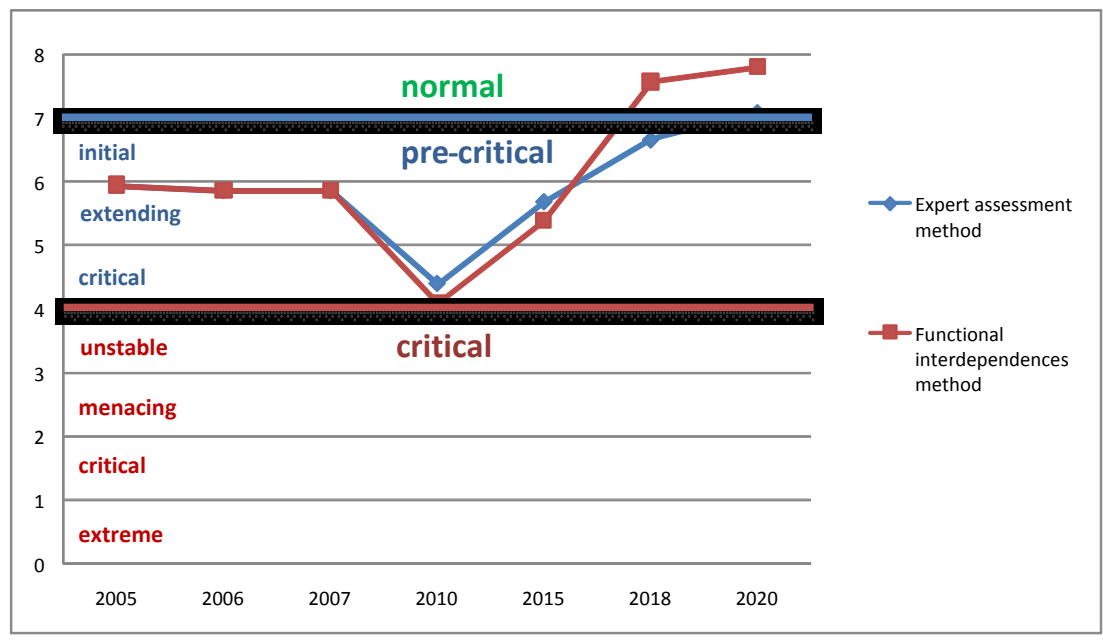

Figure 1: $\quad$ Lithuanian power supply security state for the period 2005-2020.

In future works in order to determine the state of energy supply security in the country, the indicators system should be extended and more experts' opinions and estimations should be involved.

\section{Conclusions}

1. The developed security indicators system enables one to assess security of the power supply dependence on the nuclear sector from different angles (technical, economical, socio-political and environmental).

2. Using expert assessment and functional interdependencies methods the state of Lithuanian power supply security based on nuclear energy for the period $2005-2020$ is evaluated. The state of security of power supply using expert assessment method is pre-critical in the period 2005 - 2018 and normal in 2020; using functional interdependencies method the state of security of power supply is pre-critical in the period $2005-2015$ and normal in the period $2018-2020$.

3. The lowest state of Lithuanian energy supply security will be after closing Ignalina NPP. The main factors that increase the level of security are: new connections with Sweden and Poland; new combined cycle power stations; new nuclear power plant; integration of Lithuanian electric energy system into Western Europe energy system and participation in a free electricity market.

\section{Acknowledgement}

The authors are grateful to Lithuanian State Science and Studies Foundation for partial financial support of this research. 


\section{References}

[1] Bykova, E. V. The methods of calculation and the analysis of indexes of energy security // Monograph, 2005. (Bykova E. V. Metody rascheta i analiz pokazatelei energeticheskoi bezopasnosti. Kishinev, 2005 (in Russian).)

[2] Yergin, D. Ensuring Energy Security // Foreign Affairs 85(2): pp. 69-82. 2006.

[3] Green Paper: A European Strategy for Sustainable, Competitive and Secure Energy, Brussels, 2006.

[4] Gnansounou, E. Monitoring the vulnerability of energy supply system. Proc. Of the $15^{\text {th }}$ Energy Day in Croatia - Energy Policy Scenarios for 2050, Zagreb, 26 November 2006. http://www.hed.hr/pdf/zbornik15.pdf.

[5] Scheepers, M., Seebregts, A., de Jong, J. \& Maters, H. EU standards for energy security of supply, April, 2007. http://www.clingendael.nl/ publications/2006/20060600_ciep_misc_dejong-maters-et-al.pdf.

[6] UK energy sector indicators 2008. Bureau of Business, Enterprise and Regulatory Reform, 2008. http://www.berr.gov.uk/files/file48502.pdf.

[7] Sivonen, H. Calculating Compound Risk of Failure Based on Interdependencies of Critical Infrastructures // EAPC / PfP Workshop on Critical Infrastructure Protection and Civil Emergency Planning in Zurich on 9-11 September 2004.

[8] Colli, A., Serbanescu D. \& Ale B.J.M. Indicators to compare risk expressions, grouping, and relative ranking of risk for energy systems: Application with some accidental events from fossil fuels // Safety Science, 2008, doi:10.1016/j.ssci.2008.07.022.

[9] Burgherr, P., Hirschberg, S., Brukmajster, D. \& Hampel, J. Survey of criteria and indicators. New Energy Externalities Developments for Sustainability (NEEDS) // Deliverable D1.1-Stream Research $R S 2 b$ : Energy technology roadmap and stakeholders' perspective, Paul Scherrer Institut, Villigen PSI (Switzerland), 2005.

[10] Augutis, J., Krikštolaitis, R., Matuzienè, V. \& Pečiulytė, S. Mathematical simulation of energy supply disturbances // Safety, reliability and risk analysis: theory, methods and applications: proceedings of the European safety and reliability conference (ESREL 2008), Valencia, Spain, September 22-25, 2008. London: CRC Press Taylor \& Francis Group, 1. ISBN 978-0-415-48513-5, pp. 2575-2580, 2008.

[11] Molis, A. Future ESDP Scenarios and Interests of the Small States // Politologija, 4, pp. 54-83, 2006. ISSN 1392-1681.

[12] Jakeliūnas, T. \& Molis, A. Energy security of Lithuania: challenges and perspectives // Lithuanian political science yearbook. pp. 200-223, 2005.

[13] Checchi, A., Behrens, A. \& Egenhofer Ch. Long-Term Energy Security Risks for Europe: A Sector-Specific Approach. CEPS working document. No. 309 / January 2009. http://www.ceps.eu. 
[14] Augutis, J. \& Ušpuras, E. Risk of technologies: monograph. Kaunas: Lithuanian energy institute, Vytautas Magnus University, 2006. ISBN 9986-492-89-0 (in Lithuanian).

[15] Alzbutas, R., Kupčiūnienè K., Adlytè, R. \& Augutis J. The Aircraft Crash on the Ignalina NPP Probability Estimation Considering Data Uncertainty // Energetika. 1, pp. 1-9, 2007. ISSN 0235-7208 (in Lithuanian). 